\title{
INDEKS KEPUASAN MASYARAKAT PADA PELAYANAN PUSKESMAS KOTA JAMBI
}

\section{Satisfaction Index In Public Health Center Jambi}

\author{
Rumita Ena Sari ${ }^{1}$, Sri Astuti Siregar ${ }^{1}$, Guspianto ${ }^{1}$
}

${ }^{1}$ Program Studi Ilmu Kesehatan Masyarakat, Universitas Jambi

\begin{abstract}
Abstrak
Pelayanan publik harus memuaskan penggunanya yaitu masyarakat. Salah satu bentuk pelayanan publik dalam bidang kesehatan adalah pelayanan puskesmas. Berdasarkan hasil wawancara dengan 30 orang pasien di 5 puskesmas Kota Jambi, pasien mengeluhkan lambatnya pelayanan, petugas yang tidak ramah, waktu tunggu yang lama, kursi ruang tunggu yang sedikit, dan masih banyak masalah lain yang menyebabkan pasien kurang nyaman dan tidak puas dengan pelayanan puskesmasPenelitian ini merupakan penelitian survey dengan sampel sebanyak 2000 responden di 20 puskesmas Kota Jambi. Sampel dihitung dengan rumus survey kepuasan masyarakat sesuai dengan Permenpan RB No 44 Tahun 2017. Teknik pengambilan sampel dilakukan dengan accidental. Berdasarkan hasil penelitian, didapatkan dua puskesmas dengan indeks kepuasan masyarakat "BAIK" yaitu puskesmas simpang empat sipin dan puskesmas pakuan baru. Sebanyak 18 puskesmas dengan indeks kepuasan masyarakat "KURANG BAIK". Saran dalam penelitian ini agar puskesmas Kota Jambi harus lebih meningkatkan nilai pada setiap unsur secara maksimal sesuai dengan Permenpan No 14 Tahun 2017.
\end{abstract}

Kata Kunci: Indeks, Kepuasan, Masyarakat, Puskesmas

\begin{abstract}
Public services must satisfy their users, namely the community. Public service in the health sector are public health center services. Based on the results of interviews with 30 patients at 5 heakth center in Jambi City, patients complained about slow service, unfriendly officers, long waiting times, few waiting room chairs, and many other problems that caused patients to be uncomfortable and dissatisfied with services. This study was survey research with sample 2000 respondents in 20 health centers. The sample was calculated used community satisfaction survey formula in accordance to Permenpan RB No. 44 of 2017. The sampling technique was carried out by accidental. Based on the results of the study, there were two health centers with a "GOOD" community satisfaction index, namely the Simpang Empat Sipin Health Center and the Pakuan Baru Health Center. Furthermore, a total of 18 health centers with a community satisfaction index "LESS GOOD". This research suggested that the Jambi City Puskesmas should further increase the value of each element to the maximum in accordance with Permenpan No. 14 of 2017.
\end{abstract}

Keywords : Index, Satisfaction, Public, Health Center

$\begin{array}{ll}\text { Korespondensi } & \text { : Rumita Ena Sari } \\ \text { Email } & \text { : Rumita_ena@unja.ac.id }\end{array}$




\section{PENDAHULUAN}

Pelayanan publik adalah segala bentuk pelayanan yang diberikan oleh pemerintah kepada masyarakat dalam upaya memenuhi kebutuhan masyarakat sesuai dengan peraturan perundangundangan yang berlaku ${ }^{(1)}$. Pemerintah memberikan pelayanan public dalam segala aspek kehidupan masyarakat seperti pendidikan, perbankan, hukum, ekonomi dan kesehatan. Dalam bidang kesehatan, bentuk pelayanan publik yang diberikan adalah pelayanan kesehatan, salah satunya adalah pelayanan puskesmas.

Pelayanan publik yang diberikan oleh aparatur pemerintah dirasakan belum dapat memenuhi harapan masyarakat. Banyak keluhan yang disampaikan masyarakat yang terangkum dalam media cetak maupun media elektronik hingga ke jaringan media sosial sebagai bentuk kekecewaan terhadap pelayanan pemerintah. Kondisi ini apabila dibiarkan berlarut larut, maka akan muncul rasa tidak percaya masyarakat kepada pemerintah. Maka dari itu, untuk menjaga kualitas pelayanan pemerintah yang dapat memuaskan masyarakat, maka disusunlah survey kepuasan masyarakat sebagai gambaran kinerja pelayanan yang diberikan $^{(2)}$.

Salah satu bentuk pelayanan public yang diberikan pemerintah dalam bidang kesehatan adalah pelayanan puskesmas. Menurut Permenkes Nomor 44 Tahun 2016 tentang pedoman manajemen puskesmas, puskesmas merupakan ujung tombak pelayanan kesehatan masyarakat dengan berupaya meningkatkan kesadaran masyarakat agar senantiasa hidup sehat dan memperoleh derajat kesehatan yang sangat optimal (2). Puskesmas harus memberikan pelayanan yang dapat memberikan rasa aman, nyaman dan puas bagi masyarakat.

Di Kota Jambi, disediakan sebanyak 20 unit puskesmas baik perawatan dan non perawatan yang tersebar di 11 kecamatan, dan 62 kelurahan. Jumlah penduduk Kota Jambi pada tahun 2018 sebesar 300.566 jiwa. Berdasarkan hasil wawancara dengan 30 orang pasien di 5 puskesmas Kota Jambi, pasien mengeluhkan lambatnya pelayanan, petugas yang tidak ramah, waktu tunggu yang lama, kursi ruang tunggu yang sedikit, dan masih banyak masalah lain yang menyebabkan pasien kurang nyaman dan tidak puas dengan pelayanan puskesmas.

Berdasarkan hasil penelitian yang dilakukan oleh Putra, 2016, dari 9 unsur penilaian imdeks kepuasan masyarakat ada 5 unsur yang diberikan kurang baik di Puskesmas Serang. ${ }^{(3)}$ Penelitian ini bertujuan untuk mengukur nilai indeks kepuasan masyarakat pada pelayanan puskesmas di Kota Jambi

\section{METODE PENELITIAN}

Penelitian ini merupakan penelitian survei dengan memberikan angket kepada masyarakat yang sudah pernah memanfaatkan pelayanan puskesmas di Kota Jambi. Penelitian dilaksanakan di Kota Jambi. Tempat penelitian dilakukan di 20 Puskesmas yang melayani masyarakat.

Populasi dalam penelitian ini adalah seluruh masyarakat yang pernah memanfaatkan pelayanan puskesmas di Kota Jambi. Dalam penelitian ini sampel diambil menggunakan teknik accidental sampling, yang berarti teknik pengambilan sampel atau responden yang sedang memanfaatkan pelayanan pada saat penelitian. Perhitungan sampel dalam 
penelitian ini disesuaikan dengan rumus dalam peraturan kementrian pemberdayaan dan aparatur negara no 14 tahun 2017 yaitu 100 responden pada setiap puskesmas. Total sampel dalam penelitian ini sejumlah 2000 responden. Analisa data menggunakan perangkat SPSS.

\section{HASIL PENELITIAN}

Responden yang dilibatkan dalam penelitian ini berjumlah 2000 orang yang pernah memanfaatkan pelayanan puskesmas di kota Jambi. Jumlah puskesmas yang ada di Kota Jambi sebanyak 20 unit. Berdasarkan hasil penelitian, umur tertinggi responden berada pada kelompok 35-44 tahun dengan proporsi sebanyak $36 \%$, dan jenis kelamin responden di dominasi oleh perempuan sebanyak 56,9\%. Adapun tingkat Pendidikan tertinggi responden dalam penelitian ini adalah tamat SLTA dengan proporsi $49,1 \%$ dan mayoritas responden bekerja dengan proporsi $67,9 \%$.

Nilai indeks kepuasan puskesmas pada pelayanan puskesmas berdasarkan indikator yang ada pada KEPMEN Pendayagunaan aparatur negara pada Tahun 2019 yang terdiri dari 9 bagian pelayanan, akan dijelaskan pada tabel dibawah ini ${ }^{(4)}$ :

\section{Indeks}

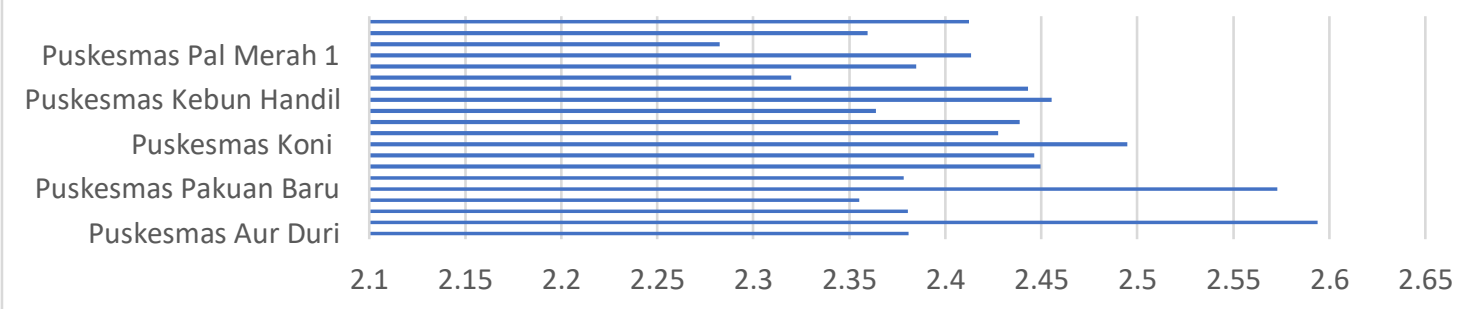

Gambar 1. Indeks Kepuasan Masyarakat Pada Pelayanan Puskesmas

Berdasarkan tabel diatas, didapatkan dua puskesmas dengan indeks kepuasan masyarakat "BAIK" yaitu puskesmas simpang empat sipin dan puskesmas pakuan baru. Sebanyak 18 puskesmas dengan indeks kepuasan masyarakat "KURANG BAIK".

\section{PEMBAHASAN}

Berdasarkan hasil penelitian, 18 puskesmas berada pada kategori indeks yang kurang baik. Hanya 2 puskesmas yang berada pada kategori baik. Indeks kepuasan masyarakat terhadap pelayanan Puskesmas merupakan salah satu komponen yang representatif dari pelayanan yang diberikan harus memberikan pelayanan yang bermutu dan mudah dijangkau dengan mengutamakan kepuasan penggunanya (5). Pelayanan public menjadi tanggung jawab pemerintah yang di dalamnya merupakan serangkaian pelayanan yang sesuai dengan standar (6).

Kepuasan konsumen adalah suatu perasaan dimana pelanggan mendapatkan pelayanan yang diharapkan atau melebihi kebutuhan pelanggan/konsumen. Kepuasan juga merupakan tingkat perasaan dimana seseorang menyatakan hasil perbandingan atas kinerja produk jasa) yang diterima dan yang diharapkan ${ }^{(7)}$. 
Penelitian ini sejalan dengan penelitian yang dilakukan oleh Nesimnasi, dkk (2019) di Puskesmas Oepoi Kota Kupang bahwa didapatkan nilai kumulatif sembilan unsur indeks kepuasan masyarakat sebesar 76,62 dengan kategori mutu pelayanan "B" atau telah berada dalam kategori kinerja unit pelayanan yang baik. Kelemahan pelayanan publik di Puskesmas tersebut menurut responden terletak pada kondisi sarana prasarana yang kurang lengkap, petugas yang belum cekatan, serta jumlah Poli yang masih belum terpenuhi sesuai kebutuhan masyarakat $^{(8)}$. Kurdi (2016) juga menyatakan dalam penelitiannya tentang Pengukuran Indeks Kepuasan Masyarakat (IKM) di Puskesmas Pamarayan Kabupaten Serang, dimana secara umum kinerja pelayanan di Puskesmas Pamarayan, berdasarkan persepsi dari masyarakat pelanggannya, memiliki kualitas baik yang terdapat pada unsur kemudahan prosedur pelayanan ${ }^{(9)}$.

Pelayanan yang memuaskan dan berkualitas akan membentuk loyalitas pelanggan. Kepuasan juga sangat erat hubungannnya dengan "word of mouth" sehingga dapat mendatangkan pelanggan baru yang selanjutnya akan meningkatkan citra Puskesmas agar dapat dipercaya ${ }^{(10)}$.

Penelitian serupa juga dilakukan oleh Fahamsyah dkk (2018) dimana seluruh Puskesmas di Kabupaten Hulu Sungai Utara mempunyai nilai IKM dengan kategori baik dan mendapatkan hasil kategori cukup puas dengan menggunakan $\mathrm{CSI}^{(11)}$. Hamka melakukan analisis indeks kepuasan masyarakat terhadap pelayanan kesehatan di Puskesmas Amahai Kabupaten Maluku Tengah dan menemukan hasil yang sama dengan penelitian ini yaitu berada dalam kategori baik $^{(12)}$.
Puskesmas dalam tatanan sistem pelayanan kesehatan di Indonesia merupakan pelaksana pelayanan tingkat pertama atau primer. Salah satu tugas pokok dan fungsi Puskesmas adalah melaksanakan upaya kesehatan masyarakat (UKM) yang merupakan pelayanan dengan sasaran masyarakat secara keseluruhan beserta lingkungan kesehatannya ${ }^{(13)}$. Selain itu, dalam Permenkes No.71/2013 dinyatakan bahwa Puskesmas merupakan fasilitas kesehatan tingkat pertama yang harus menyelenggarakan pelayanan kesehatan komprehensif yang sifatnya perorangan ${ }^{(14)}$. Pelayanan yang diberikan oleh puskesmas harus sesui dengan kebutuhan dan harapan konsumen agar tercipta kepuasan pasien. Ketidakpuasan pasien disebabkan dengan adanya kesenjangan dari pelayanan yang diberikan oleh puskesmas yang tidak sesuai dengan harapan yang dirasakan oleh konsumen, dengan adanya kesenjangan yang diberikan oleh puskesmas tersebut sehingga menimbulkan adanya penilaian yang negatif dari konsumen terhadap pelayanan dan harapan konsumen untuk memakai jasa tersebut akan berkurang ${ }^{(15)}$.

Menilai kualitas pelayanan harus dari sudut pandang pelanggan. Dengan mengetahui kepuasan pasien/pelanggan dapat mengevaluasi rating Puskesmas serta menemukan bagian mana yang membutuhkan peningkatan ${ }^{(10)}$.

\section{KESIMPULAN DAN SARAN}

Berdasarkan hasil penelitian, sebanyak 18 puskesmas berada dalam kategori indeks kurang baik, dan 2 puskesmas ada dalam kategori indeks baik. Penelitian ini menyarankan agar puskesmas Kota Jambi harus lebih meningkatkan pemenuhan nilai pada setiap 
unsur secara maksimal sesuai dengan Permenpan No 14 Tahun 2017.

\section{DAFTAR PUSTAKA}

1. Negara LA. Pelayanan Publik Di Indonesia. 1998.

2. Kementrian Kesehatan RI. PERATURAN MENTERI KESEHATAN REPUBLIK INDONESIA NOMOR 44 TAHUN 2016 TENTANG PEDOMAN MANAJEMEN PUSKESMAS. J Knowl Manag [Internet]. 2016;2(2):118. Available from: http://www.waset.org/publications/11 070\%0Ahttp://btd.egc.ufsc.br/\%0Ahtt p://dx.doi.org/10.1016/j.jdmm.2015.1 2.005\%0Ahttps://portal.aenormas.aen or.com/revista/pdf/abr16/10abr16.pdf \%0Ahttp://dx.doi.org/10.1016/j.sbspro .2014.07.296\%0Ahttps://pdfs.semanti cscho

3. Eka S. Community Satisfaction Index in Health Services at Community Health Service Serang Kota. 2016. $119 \mathrm{p}$.

4. Kementerian Pendayagunaan Aparatur Negara RI PM. Permenpam No, 14 Tahun 2017. 2017;

5. Kuupiel D, Bawontuo V, MashambaThompson TP. Improving the Accessibility and Efficiency of Pointof-Care Diagnostics Services in Lowand Middle-Income Countries: Lean and Agile Supply Chain Management. Diagnostics [Internet]. 2017;7(4):58. Available from: https://search.proquest.com/docview/1 988597983 ?accountid $=50257$

6. Lai PBS. Clinical governance in action. Vol. 21, Surgical Practice. 2017. 3 p.

7. Aveyard H, Sharp P. A Beginner's Guide to Evidence Based Practice in
Health and Social Care Profession. Vol. 1, Open University Press McGraw-Hill Education McGraw-Hill House. 2009. 1-159 p.

8. Harahap HK. Analisis Indeks Kepuasan Pasien Rawat Inap di Rumah Sakit Umum Daerah (RSUD) Gunung Tua Kabupaten Padang Lawas Utara Tahun 2017. 2018;

9. Kurdi M. Pengukuran Indeks Kepuasan Masyarakat (IKM) di Puskesmas Pamarayan Kabupaten Serang. J Lingk Widyaiswara. 2016;3(2):22-6.

10. Rangkuti F. Measuring Customer Satisfaction; Gaining Customer Relationship Strategy. 1st ed. Jakarta: Gramedia Pustaka Utama; 2006.

11. Fahamsyah, D, Hatta, C.I M. Utara, Pengukuran Indeks Kepuasan Masyarakat (IKM) Pelayanan Kesehatan di Puskesmas Kabupaten Hulu Sungai. J Adm Kesehat Indones. 2018;6(2).

12. Hamka. Analisis Indeks Kepuasan Masyarakat Terhadap Pelayanan Kesehatan di Puskesmas. Glob Heal Sci. 2016;1(2):38-35.

13. Gani A, Zahrina, Ali Bahjuri P, Siahaan RGM. Penguatan pelayanan kesehatan dasar di puskemas [Internet]. Direktorat Kesehatan dan Gizi Masyarakat. 2018. 125 p. Available from: https://www.bappenas.go.id/files/1715 13974/8326/Buku_Penguatan_Pelayan an_Kesehatan_Dasar_di_Puskesmas_Direktorat_Kesehatan_dan_Gizi_Ma syarakat_Bappenas.pdf

14. Indonesia KR. PELAYANAN KESEHATAN PADA JAMINAN KESEHATAN NASIONAL [Internet]. 2013 p. 1689-99. Available from: 
/citations?view_op=view_citation\&co ntinue $=/$ scholar $\% 3$ Fhl $\% 3 \mathrm{Dpt}-$ BR\%26as_sdt\%3D0,5\%26scilib\%3D $1 \&$ citilm $=1 \&$ citation_for_view $=w S 0 x$ i2wAAAAJ $: 20 s O g N Q 5 q M E C \& h l=p t-$ BR\&oi=p

15. Supriyanto S. Pemasaran Industri Jasa Kesehatan. HS O, editor. Jogjakarta: Andi; 2010. 